Article

\title{
Effect of Blast-Furnace Slag Replacement Ratio and Curing Method on Pore Structure Change after Carbonation on Cement Paste
}

\author{
Junho Kim ${ }^{1}\left(\right.$, Seunghyun $\mathrm{Na}^{2}$ and Yukio Hama ${ }^{3, * \mathbb{C}}$ \\ 1 Department of Architecture, National Institute of Technology, Oyama College, Nakakuki, Oyama-shi, \\ Tochigi 323-0806, Japan; kim@oyama-ct.ac.jp \\ 2 Institute of Industrial Science, The University of Tokyo, 4-6-1 Komaba, Meguro-ku, Tokyo 153-8505, Japan; \\ nash1122@naver.com \\ 3 College of Environmental Technology, Graduate School of Engineering, Muroran Institute of Technology, \\ 27-1 Mizumoto, Muroran 050-8585, Japan \\ * Correspondence: hama@mmm.muroran-it.ac.jp; Tel.: +81-143-46-5211
}

Received: 11 September 2020; Accepted: 21 October 2020; Published: 27 October 2020

\begin{abstract}
The frost damage resistance of blast-furnace slag (BFS) cement is affected by carbonation. Hence, this study investigates the carbonation properties of pastes incorporating BFS with different replacement ratios, such as $15 \%, 45 \%$, and $65 \%$ by weight, and different curing conditions, including air and carbonation. The BFS replacement ratio properties, determined by the $\mathrm{Ca} / \mathrm{Si}$ ratio of calcium silicate hydrate in the cement paste sample, were experimentally investigated using mercury intrusion porosimetry, X-ray diffraction, and thermal analysis. The experimental investigation of the pore structure revealed that total porosity decreased after carbonation. In addition, the porosity decreased at a higher rate as the BFS replacement rate increased. Results obtained from this study show that the chemical change led to the higher replacement rate of BFS, which produced a higher amount of vaterite. In addition, the lower the $\mathrm{Ca} / \mathrm{Si}$ ratio, the higher the amount of calcium carbonate originating from calcium silicate hydrate rather than from calcium hydroxide. As a result of the pore structure change, the number of ink-bottle pores was remarkably reduced by carbonation. Comparing the pore structure change in air-cured and carbonation test specimens, it was found that as the replacement rate of BFS increased, the number of pores with a diameter of $100 \mathrm{~nm}$ or more also increased. The higher the replacement rate of BFS, the higher the amount of calcium carbonate produced compared with the amount of calcium hydroxide produced during water curing. Due to the generation of calcium carbonate and the change in pores, the overall number of pores decreased as the amount of calcium carbonate increased.
\end{abstract}

Keywords: blast-furnace slag; carbonation; pore structure

\section{Introduction}

The Ca/Si ratio of C-S-H (calcium silicate hydrate) affects the properties of cement and cementitious materials. When the amount of blast-furnace slag (BFS) increases, the $\mathrm{Ca} / \mathrm{Si}$ ratio of $\mathrm{C}-\mathrm{S}-\mathrm{H}$ in the cement composite decreases. Many studies have focused on the characteristics of the $\mathrm{Ca} / \mathrm{Si}$ ratio of $\mathrm{C}-\mathrm{S}-\mathrm{H}$. Tanaka et al. [1] found that the density of $\mathrm{C}-\mathrm{S}-\mathrm{H}$ is proportional to the $\mathrm{Ca} / \mathrm{Si}$ ratio, and it is not related to the environment of $\mathrm{C}-\mathrm{S}-\mathrm{H}$ hydration. Ishida et al. [2] reported that the $\mathrm{Ca} / \mathrm{Si}$ ratio did not affect the carbonation speed.

$\mathrm{The} \mathrm{Ca} / \mathrm{Si}$ ratio has an impact even after curing. In particular, concrete shows a low resistance to carbonation in an accelerated environment caused by a lower $\mathrm{Ca} / \mathrm{Si}$ ratio. Many researchers have studied the relationship between compressive strength and durability during the carbonation of 
cement. In previous studies [3-5], the carbonation of concrete was examined, and it was found that the pore structure dramatically changed after carbonation. In addition, Phung et al. [6] found that the carbonation-induced change affects the microstructure of the concrete and decreases its water permeability. Borges et al. [7] revealed that the durability of concrete increases as the curing temperature increases and that the porosity within the cement mixture decreases after carbonation, whereas the density of the cement paste increases. Rostami et al. [8] reported that carbonation improves strength and durability. Zhang et al. [9] experimentally identified the resistance to freeze-thaw with and without carbonation, and the results revealed that the reduction in weight loss is due to carbonation. However, the effects of the change in chemical composition have not been considered. Therefore, it is necessary to determine the effects of the change in chemical composition on pore structure.

In this study, which aims to determine the suitable pore structure involved in the carbonation of BFS-blended cementitious composites, the effects of different pore structures and hydration products on the carbonation of cement paste samples are studied using Mercury Intrusion Porosimetry (MIP), X-ray diffraction (XRD) analysis, and thermal analysis (TG-DTA). The results obtained from this study provide invaluable information regarding the durability of cementitious composites, offering a better understanding of the carbonation of BFS-blended cementitious composites.

\section{Experimental Program}

\subsection{Experimental Materials and Sample Preparation}

The cement used in this experiment was Ordinary Portland Cement (OPC). OPC is denoted as N with a density of $3.17 \mathrm{~g} / \mathrm{cm}^{3}$. In addition, BFS with a fineness of $3930 \mathrm{~cm}^{2} / \mathrm{g}$ (density of $2.91 \mathrm{~g} / \mathrm{cm}^{3}$ ) was used to replace OPC at $15 \%, 45 \%$, and $65 \%$ by weight. All paste specimens were cast into $50 \times 100 \mathrm{~mm}$ plastic cylinder molds with a water-binder ratio (W/B) of 0.65 without any chemical admixture. The chemical composition and physical properties of material are shown in Table 1. The mixture proportions of the paste and the dosage of mineral admixtures are shown in Table 2. Pore size distribution was determined using the mercury intrusion method and chemical composition by the XRD method. DTG (differential thermogravimetry) was used to conduct a thermal analysis. The total number of pores was also measured.

Table 1. Chemical and physical properties of material.

\begin{tabular}{|c|c|c|c|c|c|c|c|c|c|c|c|}
\hline & \multicolumn{9}{|c|}{ Chemical Composition (\%) } & \multicolumn{2}{|c|}{ Physical Properties } \\
\hline & $\mathrm{SiO}_{2}$ & $\mathrm{Al}_{2} \mathrm{O}_{3}$ & $\mathrm{Fe}_{2} \mathrm{O}_{3}$ & $\mathrm{CaO}$ & $\mathrm{MgO}$ & $\mathrm{K}_{2} \mathrm{O}$ & $\mathrm{Na}_{2} \mathrm{O}$ & $\mathrm{SO}_{3}$ & LOI & $\begin{array}{l}\text { Density } \\
\left(\mathrm{g} / \mathrm{cm}^{3}\right)\end{array}$ & $\begin{array}{c}\text { Blaine Fineness } \\
\left(\mathrm{cm}^{2} / \mathrm{g}\right)\end{array}$ \\
\hline OPC & 21.06 & 5.51 & 2.69 & 65.47 & 1.66 & 0.4 & 0.24 & 1.91 & 2.28 & 3.17 & 3390 \\
\hline BFS & 34.03 & 14.36 & 0.83 & 43.28 & 6.51 & - & - & - & 0.1 & 2.91 & 3930 \\
\hline
\end{tabular}

Table 2. Mixture design of paste samples.

\begin{tabular}{cccc}
\hline \multirow{2}{*}{ W/C } & \multicolumn{2}{c}{ Replacement Ratio (\%) } \\
\cline { 3 - 4 } & & OPC & BFS \\
\hline N & & 100 & - \\
BA & \multirow{2}{*}{0.65} & 85 & 15 \\
BB & & 55 & 45 \\
BC & & 35 & 65 \\
\hline
\end{tabular}

\subsection{Experimental Method}

\subsubsection{Mercury Intrusion Porosimetry}

The pore size distribution of the samples was determined by the MIP method, which is a method commonly used to measure the pore size distribution in cementitious composite materials [10-12]. 
The surface tension of the mercury and the mercury density were $0.480 \mathrm{~N} / \mathrm{m}$ and $13.546 \mathrm{~g} / \mathrm{mL}$, respectively, assuming a $140^{\circ}$ contact angle. The samples were exposed to $\mathrm{CO}_{2}$ in the control chamber before measurements were taken from the carbonated cement paste. The MIP technique requires that the hardened cementitious composite materials are thoroughly treated to remove water and evacuated prior to testing. After the curing, the cement paste samples were cut into $5 \mathrm{~mm}^{3}$ cubes. Acetone was used to halt the cement paste hydration reaction, and a vacuum drying treatment was administered to each sample. The pore size of each sample was measured using a porosimeter (Autopore Master33, Quantachrome instruments, Tokyo, Japan), in which a hydraulic pump was used to generate the pressure and a contact sensor was used to measure the volume of mercury. It has been sufficiently demonstrated that the effect of a sample's mass and size on the pore structure result is relatively small [13]. Moreover, the MIP measurement is highly dependent on the equipment. According to the manufacturer of the porosimeter equipment used in this study, the accuracy of this equipment in the range of $0-220 \mathrm{MPa}$ is $\pm 0.11 \%$ and the linearity in the range from 0 to maximum pressure is $\pm 0.05 \%$, which also reveals that the measurement results in this study are reliable.

\subsubsection{X-ray Diffraction}

An analysis of the hydration was conducted using the XRD method to assess various cement hydration products. The XRD characteristics and ignition loss (LOI) characteristics were measured for each curing age condition, acetone replacement was carried out to stop the hydration reaction, and the samples were dried before the measurements were taken.

Prior to XRD analysis, the samples were dried using vacuum drying equipment for $24 \mathrm{~h}$. The samples were then turned into powder using a vibration mill, and the powder samples were used to conduct the XRD analysis. For the analysis, a semiconductor-type high-speed detector was used with $\mathrm{CuK} \alpha$ as a target, a tube current of $40 \mathrm{~mA}$, a tube voltage of $45 \mathrm{kV}$, a step width of 0.02 degrees, and a $2 \theta$ scan range of $5-70^{\circ} \mathrm{C}$.

\subsubsection{Thermal Analysis}

The powder samples were used a cement paste. The heating rate was $30-1000{ }^{\circ} \mathrm{C}\left(20^{\circ} \mathrm{C} / \mathrm{min}\right)$ under a nitrogen atmosphere. The reduction in weight was measured based on the amounts of calcium carbonate (CC) and calcium hydroxide $(\mathrm{CH})$. The $\mathrm{CO}_{2}$ loss in the carbonation range of $600-750{ }^{\circ} \mathrm{C}$ was converted into a $\mathrm{CH}$ loss, and the $\mathrm{CH}$ was calculated in the dihydroxylation range of $400-500{ }^{\circ} \mathrm{C}$. Borges suggested how to measure the amounts of $\mathrm{CH}$ and CC, Equations (1)-(6). [7]

$$
\begin{aligned}
& \underset{74 \mathrm{~g} / \mathrm{mol})_{2}}{\mathrm{Ca}(\mathrm{OH}}+\underset{44 \mathrm{~g} / \mathrm{mol}}{\mathrm{CO}_{2}} \rightarrow \underset{100 \mathrm{~g} / \mathrm{mol}}{\mathrm{CaCO}_{3}}+\underset{18 \mathrm{~g} / \mathrm{mol}}{\mathrm{H}_{2} \mathrm{O}} \\
& \% \mathrm{CC}=\frac{\mathrm{dc}_{\mathrm{loss}} \cdot 100}{44}=2.27 \cdot \mathrm{dc}_{\text {loss }} \\
& \% \mathrm{CH}_{\mathrm{dc}-\mathrm{loss}}=\frac{\% \mathrm{CC} \cdot 74}{100}=\frac{2.27 \cdot \mathrm{dc}_{\text {loss }} \cdot 74}{100}=1.68 \cdot \mathrm{dc}_{\mathrm{loss}} \\
& \underset{74 \mathrm{~g} / \mathrm{mol}}{\mathrm{Ca}(\mathrm{OH})_{2}} \rightarrow \underset{56 \mathrm{~g} / \mathrm{mol}}{\mathrm{CaO}}+\underset{18 \mathrm{~g} / \mathrm{mo}}{\mathrm{H}_{2} \mathrm{O}} \\
& \% \mathrm{CH}_{\mathrm{dh}-\mathrm{loss}}=\frac{\mathrm{dh}_{\text {loss }} \cdot 74}{18}=4.11 \cdot \mathrm{dh}_{\text {loss }} \\
& \% \mathrm{CH}_{\text {total }}=\% \mathrm{CH}_{\mathrm{dc}-\text { loss }}+\% \mathrm{CH}_{\mathrm{dh}-\text { loss }}=1.68 \cdot \mathrm{dc}_{\text {loss }}+4.11 \cdot \mathrm{dh}_{\text {loss }}
\end{aligned}
$$

The amount of carbonation from $\mathrm{CH}$ and C-S-H was calculated based on the amounts of water curing, air curing, and carbonation by using Equations (7) and (8). 


$$
\begin{gathered}
\% \mathrm{CH}_{\text {initial }}=\% \mathrm{CH}+\frac{\% \mathrm{CC} \cdot 74 \mathrm{~g} / \mathrm{mol}}{100 \mathrm{~g} / \mathrm{mol}}=\% \mathrm{CH}+0.74 \% \mathrm{CC}=(\mathrm{A})+0.74 \cdot(\mathrm{B}) \\
\% \mathrm{CC}=\frac{\% \mathrm{CH} \cdot 100}{74}=1.35 \% \mathrm{CH}=1.35 \cdot(\mathrm{F})
\end{gathered}
$$

\subsection{Curing Condition}

Figure 1 shows the curing process and the sampling point in this study. The mortar sample was cut $5 \mathrm{~mm}$ from the top in order to avoid the effect of bleeding. The thickness of the test specimen was $5 \mathrm{~mm}$ in order to complete the carbonation of the entire set of test samples in a short period of time. The water-cured sample was cured in water for 2 weeks, and the air-cured sample was air cured for 6 weeks after 2 weeks of water curing. In addition, the carbonation sample was subjected to accelerated carbonation $\left(20{ }^{\circ} \mathrm{C}, \mathrm{RH} 60 \%\right.$, and $\left.5 \% \mathrm{CO}_{2}\right)$ for 6 weeks after 2 weeks of water curing. In addition, the complete carbonation of the test specimen was performed by spraying a phenolphthalein solution, and complete carbonation was confirmed.

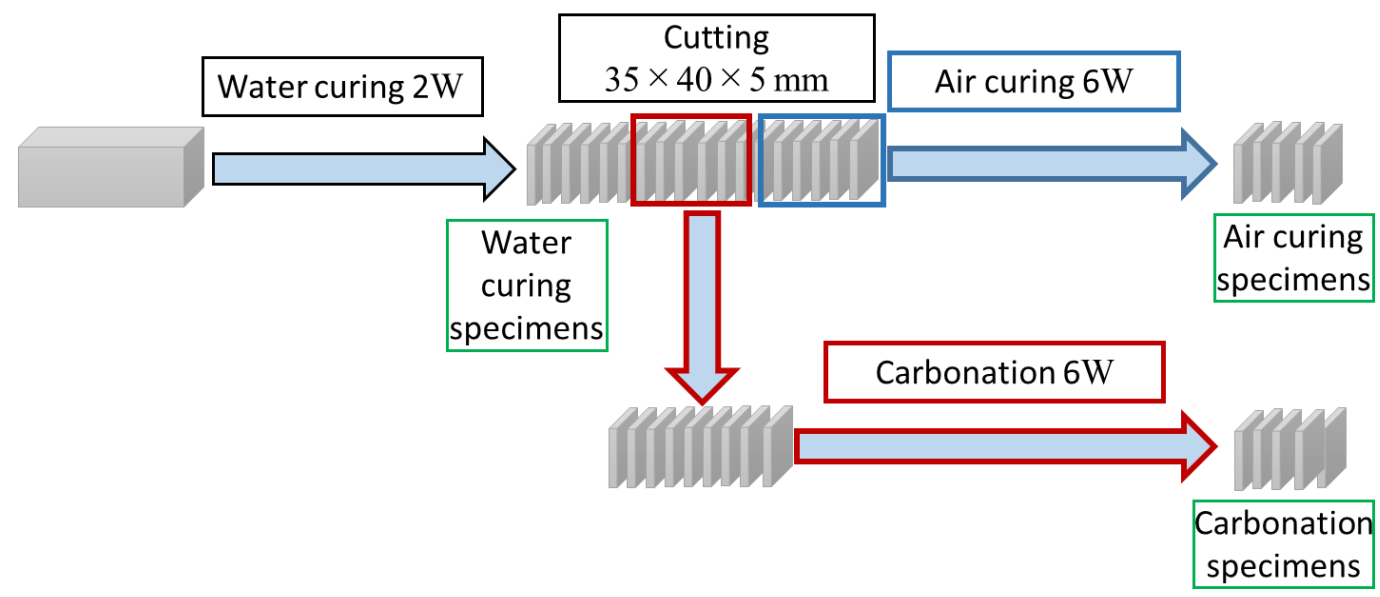

Figure 1. Curing process and sampling process.

\section{Experiment Result}

\subsection{Characteristics of Chemical Properties According to Carbonation}

\section{X-ray Diffraction Result}

Figure 2 shows the effect of the hydration products on hardened cement paste with BFS replacement ratios of $15 \%, 45 \%$, and $65 \%$ for various cement samples. The XRD data for the paste samples were collected after water curing, air curing, and carbonation, as shown in Figure 2a-d. The hydration products of cement, calcium hydroxide, calcium carbonate, and vaterite were investigated; the peaks of calcium hydroxide $\left(\mathrm{Ca}(\mathrm{OH})_{2} ; \mathrm{CH}\right.$, peaks of $\left.2 \theta=18,33.9,47\right)$, vaterite $(\mathrm{V}$, peaks of $2 \theta=25,27,33,44$, $50.5,56)$, and calcite $(C$, peaks of $2 \theta=29,39)$ were determined. As shown in Figure 2 , the $\mathrm{CH}$ peak is found in all of the cement paste samples and decreases as the proportion of BFS increases due to the additional hydration of BFS, which reacts with $\mathrm{CH}$ and generates the $\mathrm{C}-\mathrm{S}-\mathrm{H}$ gel. This reduction in calcium hydroxide inside of the cement mixed with slag was also observed when air curing was performed. The XRD data of the cement paste sample with BFS after carbonation curing are shown in Figure 2. The peak of the vaterite can more easily be observed with a higher BFS replacement ratio because the generation of vaterite under carbonation results in the decomposition of the $\mathrm{C}-\mathrm{S}-\mathrm{H}$ gel, in agreement with previous studies $[7,14]$. 


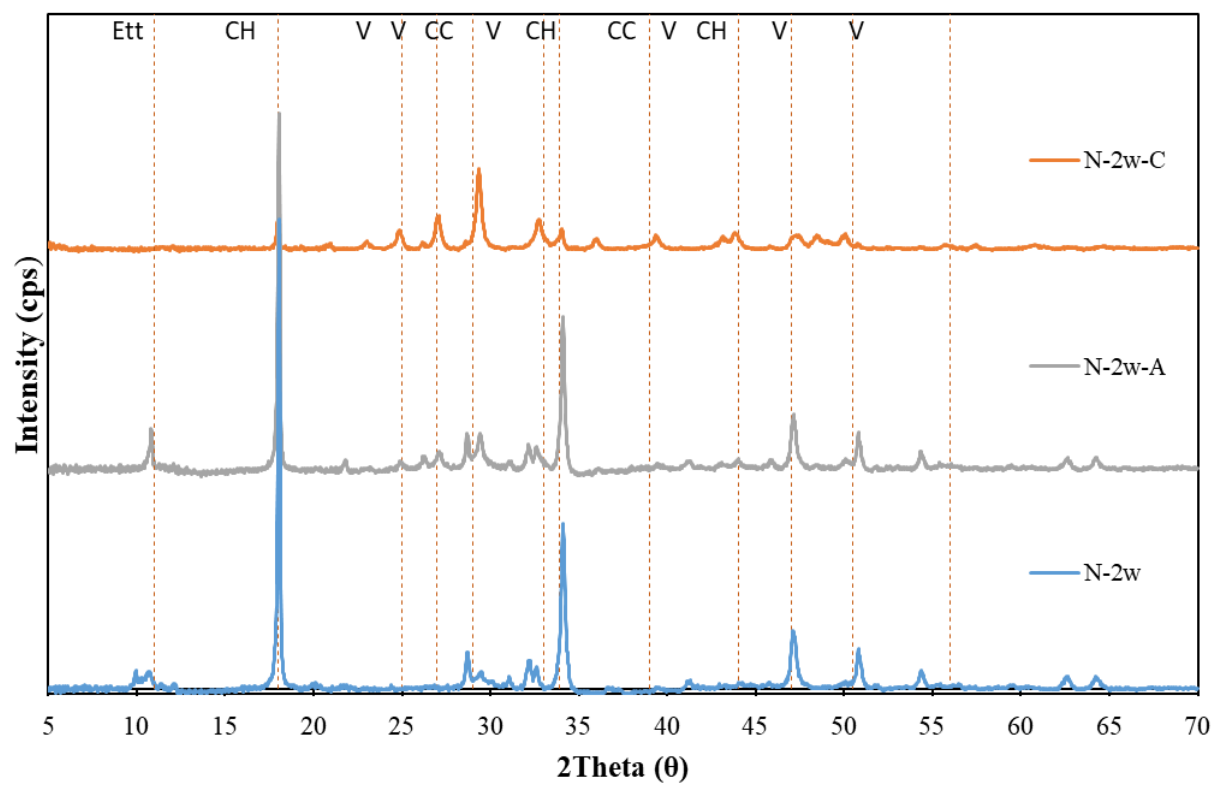

(a)

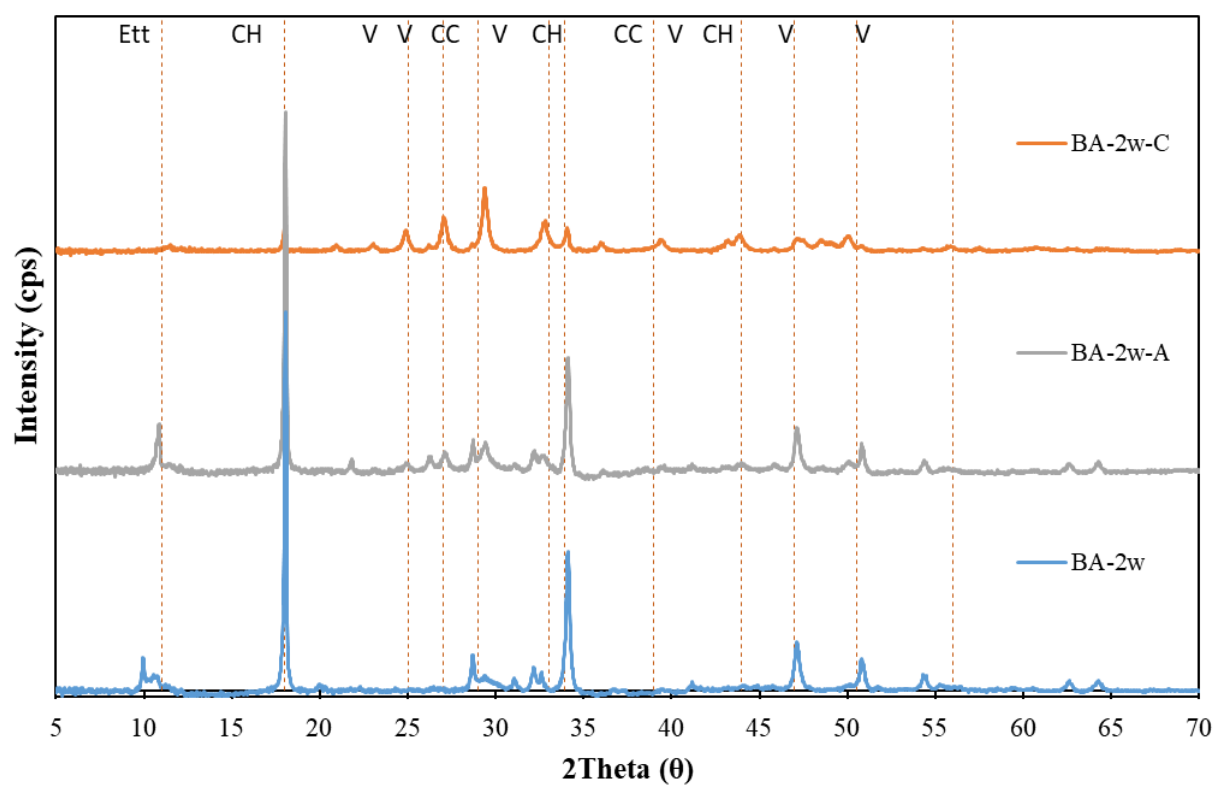

(b)

Figure 1. Cont. 


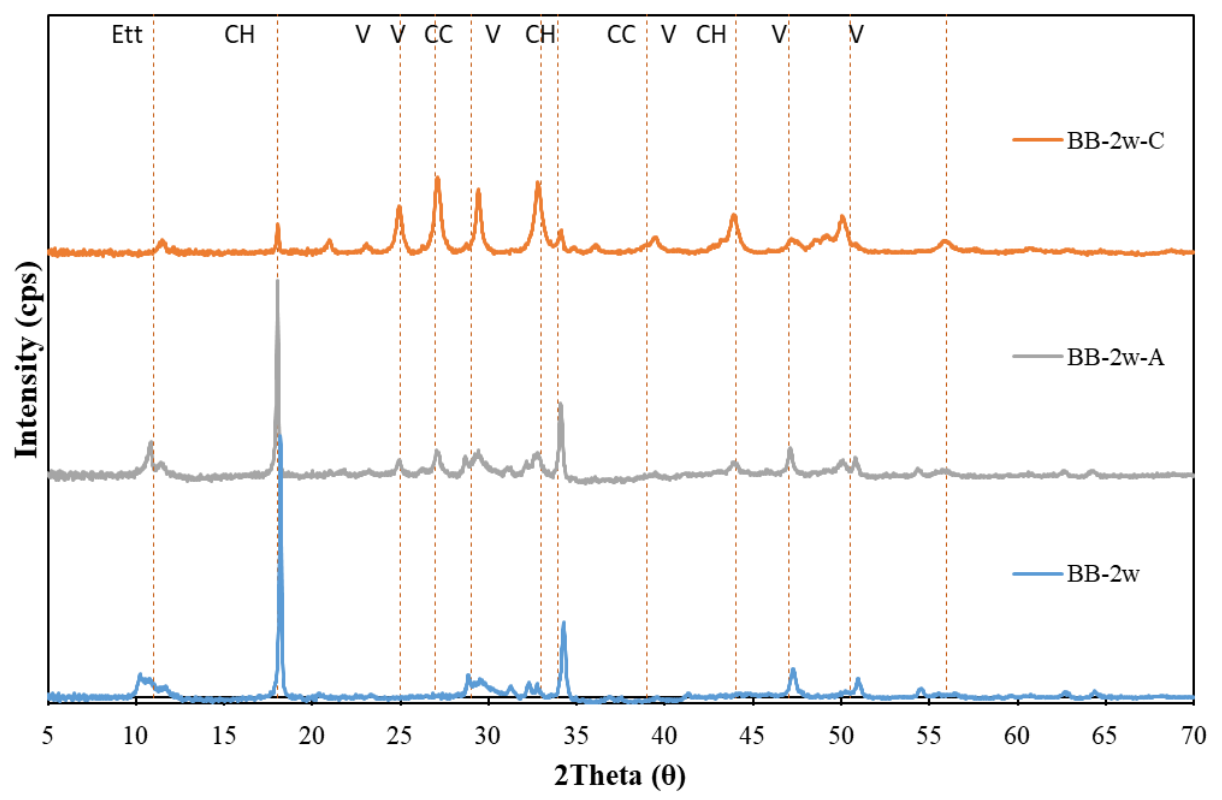

(c)

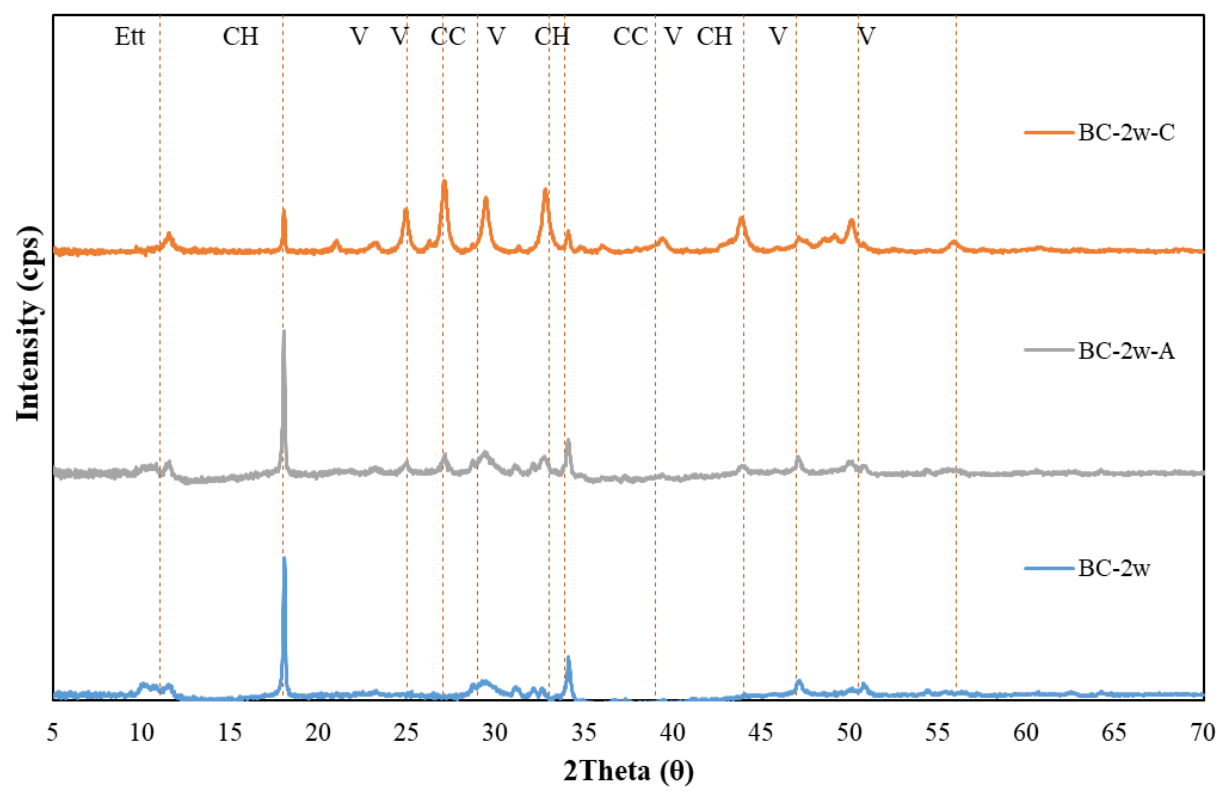

(d)

Figure 2. XRD patterns of carbonated cement paste. (a) N; (b) BA; (c) BB and (d) BC.

3.2. Characteristics of the Amount of Calcium Hydroxide and Calcium Carbonate after Carbonation

\subsubsection{DTG Curves of Calcium Hydroxide and Calcium Carbonate}

Figures 3 and 4 show the DTG results and mass loss results of the thermal analysis at a curing age of 2 weeks. We focused the investigation on calcium carbonate and calcium hydroxide. The calcium hydroxide exhibits decreased peaks in the range of $400-500{ }^{\circ} \mathrm{C}$ and the calcium carbonate exhibits decreased peaks in the range of $600-800{ }^{\circ} \mathrm{C}$. In Figure 4, the mass loss due to calcium hydroxide and calcium carbonate is confirmed. In each temperature range, a weight change owing to calcium hydroxide and calcium carbonate was observed. In addition, in the carbonation specimen, as the replacement rate of BFS increased, the overall mass loss tended to decrease. 
T $\left({ }^{\circ} \mathrm{C}\right)$

$\begin{array}{lllllllllll}0 & 100 & 200 & 300 & 400 & 500 & 600 & 700 & 800 & 900 & 1000\end{array}$

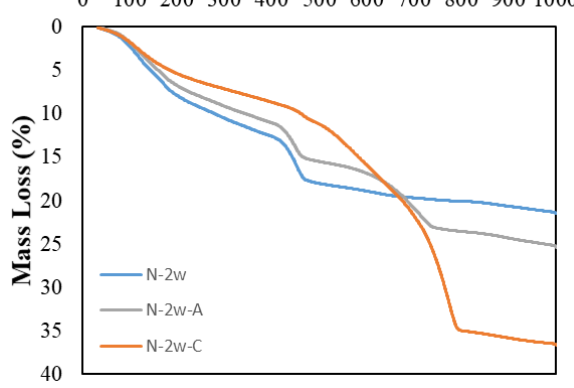

(a)

$\mathbf{T}\left({ }^{\circ} \mathrm{C}\right)$

$\begin{array}{llllllllll}0 & 100 & 200 & 300 & 400 & 500 \quad 600 & 700 & 800 & 900 & 1000\end{array}$

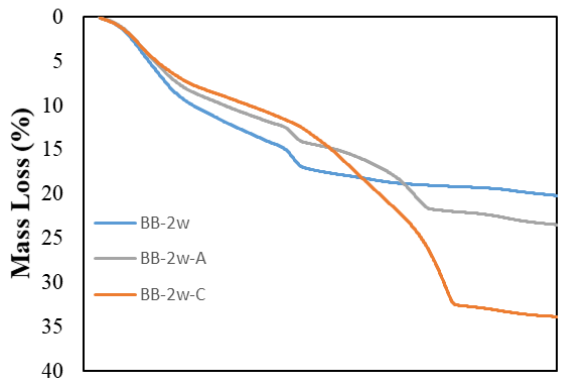

(c)
T $\left({ }^{\circ} \mathrm{C}\right)$

$\begin{array}{llllllllll}100 & 200 & 300 & 400 & 500 & 600 & 700 & 800 & 900 & 1000\end{array}$

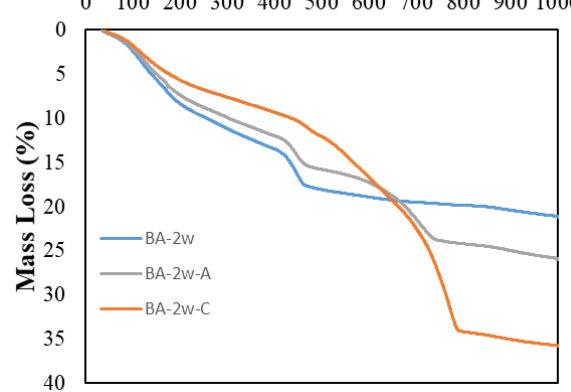

(b)

T $\left({ }^{\circ} \mathrm{C}\right)$

$0 \quad 100200300400500600 \quad 700 \quad 800 \quad 9001000$

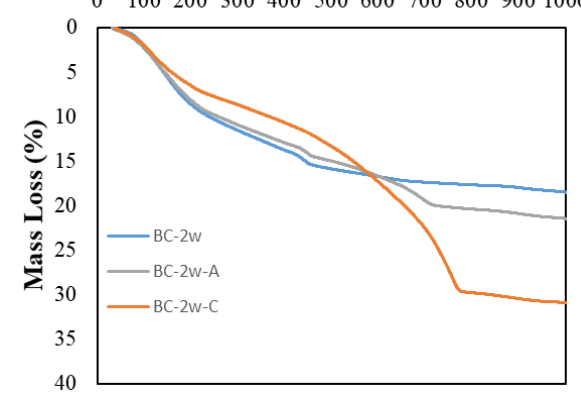

(d)

Figure 3. Mass loss of carbonated cement paste. (a) N; (b) BA; (c) BB and (d) BC.

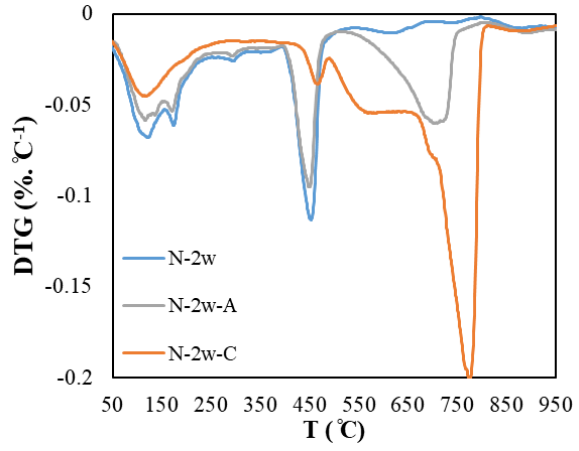

(a)

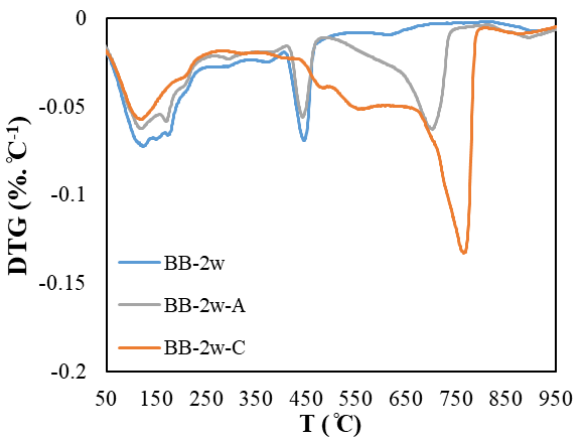

(c)

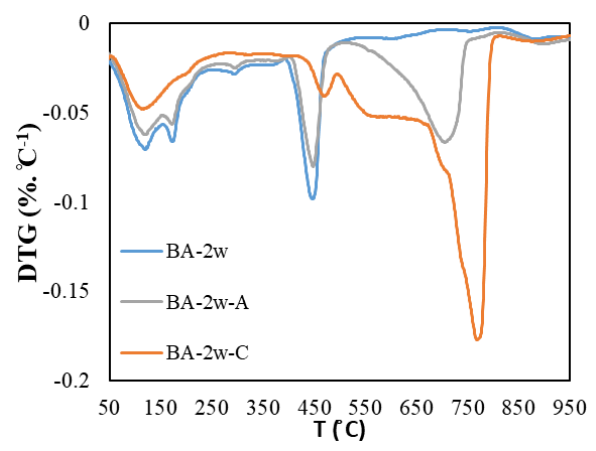

(b)

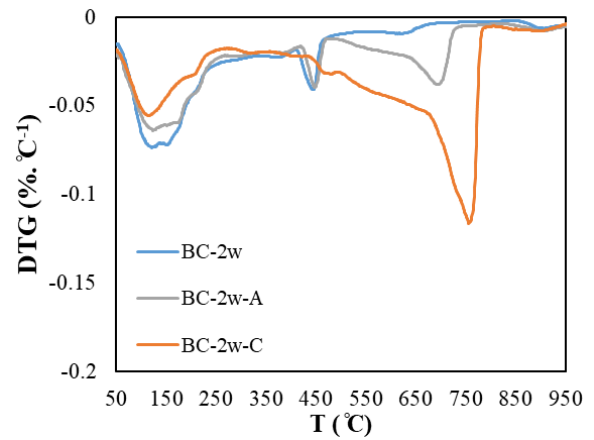

(d)

Figure 4. DTG of carbonated cement paste. (a) N; (b) BA; (c) BB and (d) BC. 
In Figure 4, which compares the water-cured specimens, it can be observed that as the replacement rate of BFS increases, the rate of $\mathrm{CH}$ formation decreases, as described by Wu. et al. in 2017 [15]. Air-cured specimens also showed the same trend; in this case, carbonation increases the CC peak and decreases the $\mathrm{CH}$ peak. It appears that the thickness of the air-cured specimen $(5 \mathrm{~mm})$, which was cut after water curing, caused the rate of carbonation to increase.

In comparing the carbonation test samples, almost no $\mathrm{CH}$ was found in the $\mathrm{BB}$ and $\mathrm{BC}$ test samples, and the CC peak of the carbonation test sample was larger than that of the water-cured and air-cured test samples. In addition, the results show that as the BFS replacement rate increases, the CC generation rate decreases. These results show the same trend as previous studies, and because the amount of $\mathrm{CC}$ varies according to the amount of $\mathrm{CH}$, it is determined that the amount of $\mathrm{CC}$ produced by the test specimen, given the small amount of $\mathrm{CH}$ produced during water curing, is also small [15].

\subsubsection{The Amount of Calcium Hydroxide and Calcium Carbonate}

Figure 5 shows the amount of calcium hydroxide $(\mathrm{CH})$ and calcium carbonate $(\mathrm{CC})$ in BFS-blended paste samples determined by thermal analysis at a curing age of 2 weeks. The replacement ratios of the BFS-blended cement paste samples included ratios of $15 \%, 45 \%$, and $65 \%$ by weight of cement. As shown in Figure 6, the amount of $\mathrm{CH}$ in the paste samples tends to decrease as the BFS replacement ratio increases because of the decreasing cement content. In the case of air curing, the amount of $\mathrm{CH}$ and CC tends to decrease according to the BFS replacement rate. In the case of carbonation, regardless of the replacement rate of BFS, a similar amount of $\mathrm{CH}$ was produced. In the case of $\mathrm{CC}, \mathrm{BB}$, and $\mathrm{BC}$, which had a high BFS replacement rate, the amount of $\mathrm{CH}$ produced was slightly lower. However, when considering the amount of $\mathrm{CH}$ generated during underwater curing and air curing, the amount of CC produced is higher than expected. This result is in agreement with previous studies, and in the specimens with a high replacement rate of BFS, it is determined that the carbonation amount by $\mathrm{C}-\mathrm{S}-\mathrm{H}$ is greater than that by $\mathrm{CH}$. [15] The same tendency was found in a previous study where a test specimen was substituted with fly ash. It is considered that this tendency occurs when C-S-H with a low $\mathrm{Ca} / \mathrm{Si}$ ratio is produced [16].

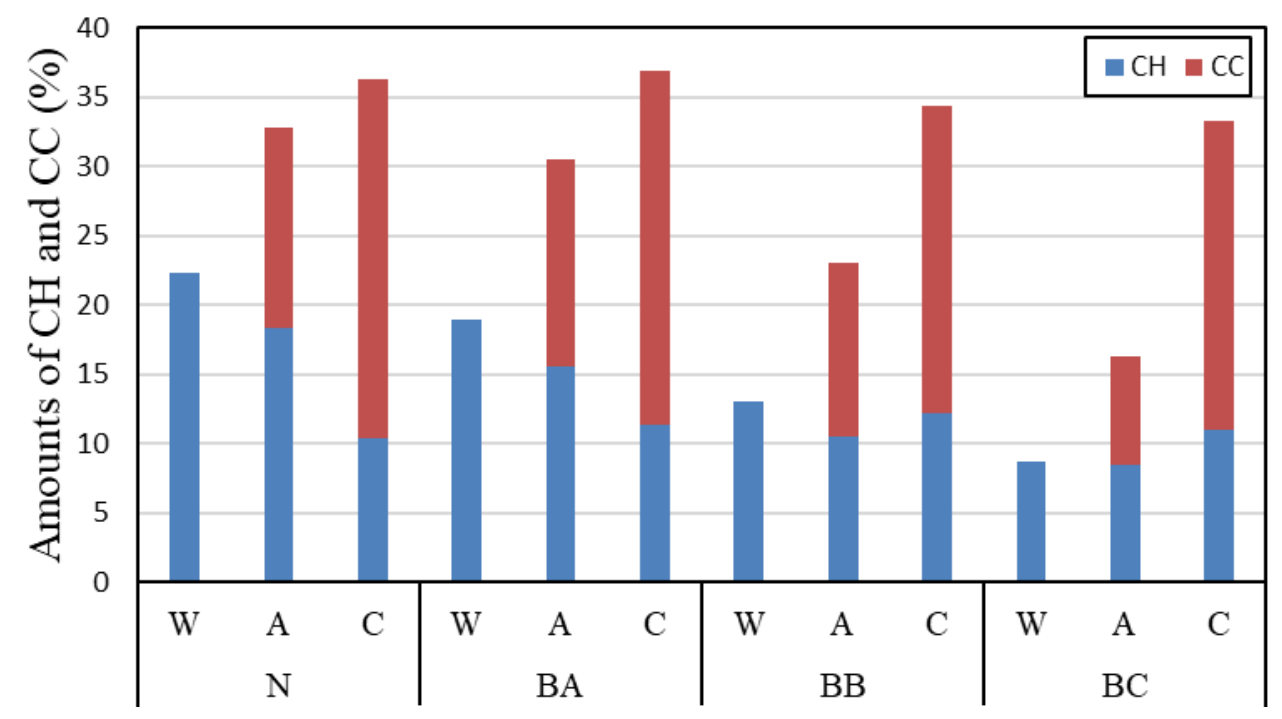

Figure 5. Amount of calcium hydrate $(\mathrm{CH})$ and calcium carbonate $(\mathrm{CC})$ in carbonated cement paste. 


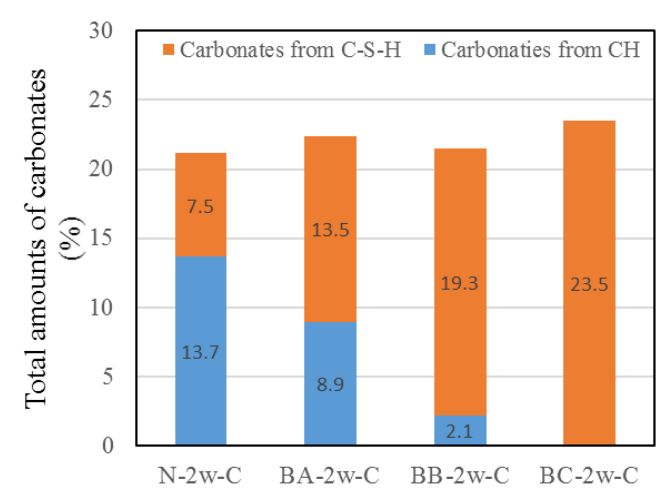

(a)

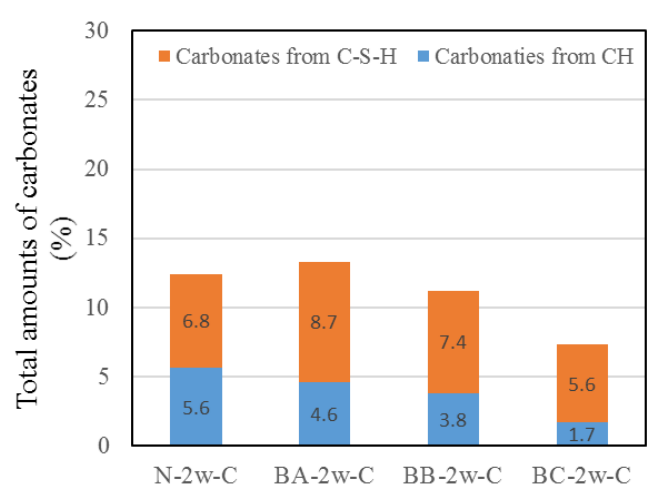

(b)

Figure 6. Carbonation of $\mathrm{CH}$ and calcium silicate hydrate $(\mathrm{C}-\mathrm{S}-\mathrm{H})$ of the paste samples with different replacement ratios of blast-furnace slag (BFS). (a) Comparison of water curing and carbonation samples and (b) Comparison of air curing and carbonation samples.

\subsubsection{Carbonation of $\mathrm{CH}$ and $\mathrm{C}-\mathrm{S}-\mathrm{H}$}

Figure 6 shows the carbonation of $\mathrm{CH}$ and $\mathrm{C}-\mathrm{S}-\mathrm{H}$ in BFS-blended paste samples at a water curing age of 2 weeks. The extent of carbonation of $\mathrm{CH}$ and $\mathrm{C}-\mathrm{S}-\mathrm{H}$ during air curing and after carbonation in the paste samples is also shown. Figure 6a shows the calculated results of the water-cured and carbonated paste samples. The results show that the carbonates from $\mathrm{C}-\mathrm{S}-\mathrm{H}$ increase as the replacement ratio of BFS increases. In the case of the $\mathrm{BC}-2 \mathrm{w}-\mathrm{C}$ paste samples, most of the carbonates formed in these samples were from $\mathrm{C}-\mathrm{S}-\mathrm{H}$. The obtained results align with those of previous studies reported in the literature $[8,16,17]$. Figure $6 \mathrm{~b}$ shows the calculated result of the amount of carbonate from $\mathrm{CH}$ and $\mathrm{C}-\mathrm{S}-\mathrm{H}$ in the water-cured and air-cured paste samples. The total carbonation amount of the paste samples tends to decrease as the BFS replacement ratio increases. In the carbonation amount from $\mathrm{C}-\mathrm{S}-\mathrm{H}$, there is a slight difference. However, when the replacement rate of BFS increases, the carbonation amount from $\mathrm{CH}$ decreases $[15,16]$.

\subsection{Characteristics of Pore Structure after Carbonation}

\subsubsection{Pore Volume of Log Differential Results}

Figure 7 shows the change in pore size distribution of the BFS-blended paste samples at a water curing age of 2 weeks. In previous studies, the effect of void structure on frost resistance was studied $[17,18]$. Therefore, it is expected that the void structure changed by carbonation will affect the durability. Figure 7a shows the pore change results for the $\mathrm{N}$ samples' carbonation (6 weeks), air curing ( 6 weeks), and water curing ( 2 weeks), respectively. It can be observed that the pore volume of the small pores (diameters of approximately $80 \mathrm{~nm}$ ) decreased as the air curing progressed, indicating that the pore structure changed according to curing age. In addition, the carbonation paste samples tended to decrease in comparison with the air-cured samples. In both the water-cured and the air-cured samples, the size of the small pores decreased and the size of the pores with diameters greater than $100 \mathrm{~nm}$ increased. This change in the pore structure is considered to be an effect of drying the specimen during air curing and after water curing. 


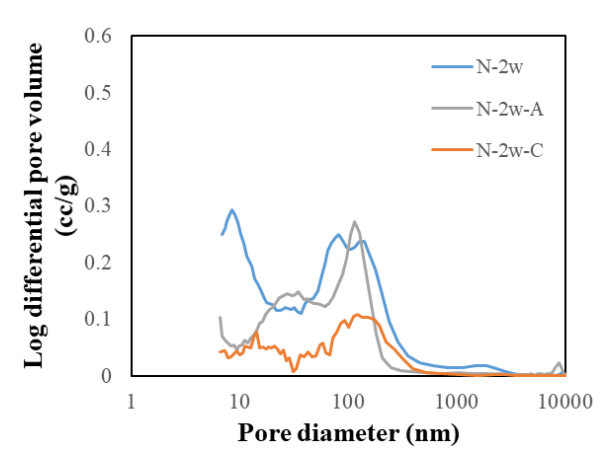

(a)

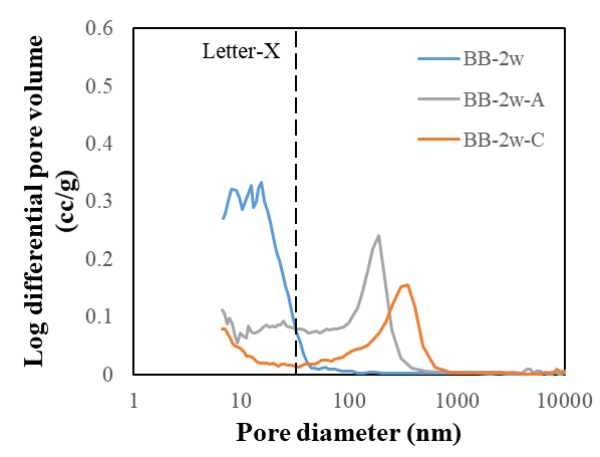

(c)

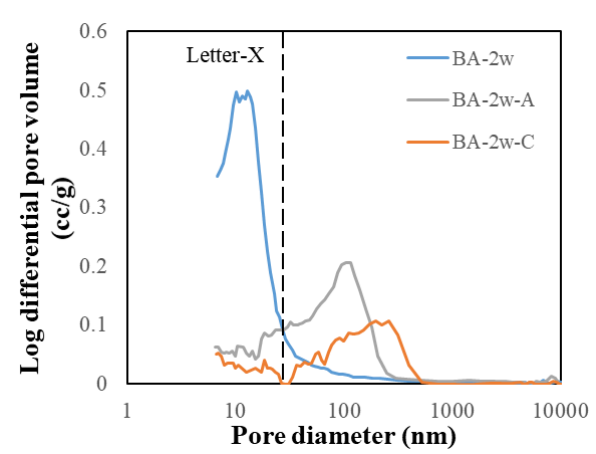

(b)

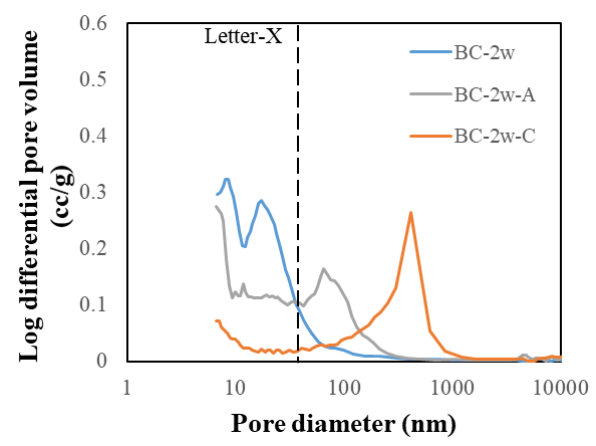

(d)

Figure 7. Pore size distributions of carbonated cement paste. (a) N; (b) BA; (c) BB and (d) BC.

Figure $7 \mathrm{~b}-\mathrm{d}$ shows the pore change results for the BFS-blended paste samples. The peak of the pore volume is higher than that of the $\mathrm{N}$ paste samples at a low pore diameter, and the pore volume of the small pores decreases after the carbonation progresses, indicating that the pore structure is changed.

These results show the same trend as previous studies, which confirmed that the peaks of the pore volume moved in the direction of the larger pore size due to the carbonation. However, the reason for this is inconclusive and requires further research [19]. In other studies, a shift in pore size of this tendency was observed, but the reason was considered to be the low amount of $\mathrm{CH}$ generation [20].

The reason for the shift of the pore peak of the air-cured specimen towards a larger pore size compared with the peak of the water-cured specimen remains unknown. Although verification is necessary, it is possible that the contraction caused by BFS may be the reason.

\subsubsection{Cumulative Pore Volume Results}

Figure 8 shows the cumulative pore volume results for the carbonation (6 weeks), air-cured (6 weeks), and water-cured samples ( 2 weeks). It is well known that the pore volume of cement-based composites depends on the cement hydration. This finding is in good agreement with the BFS-blended paste samples. In fact, cement hydration causes a decrease in the pore volume after carbonation, implying that there is a negligible effect from water curing. 


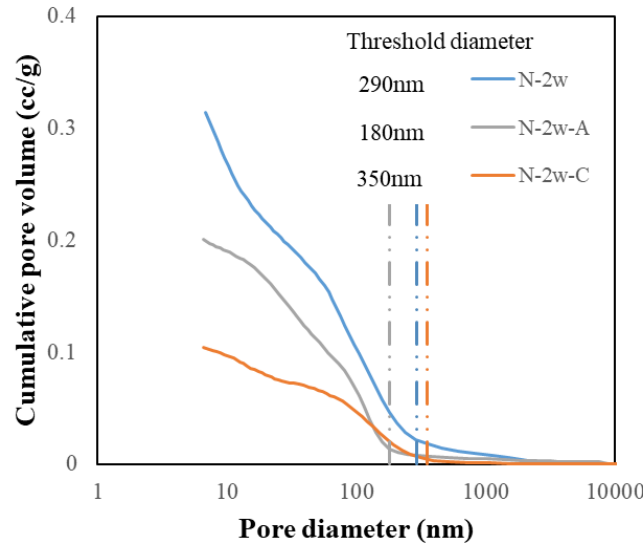

(a)

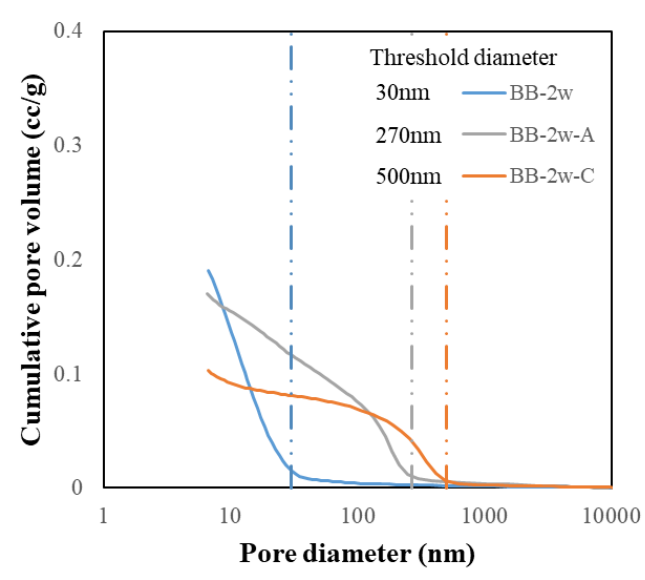

(c)

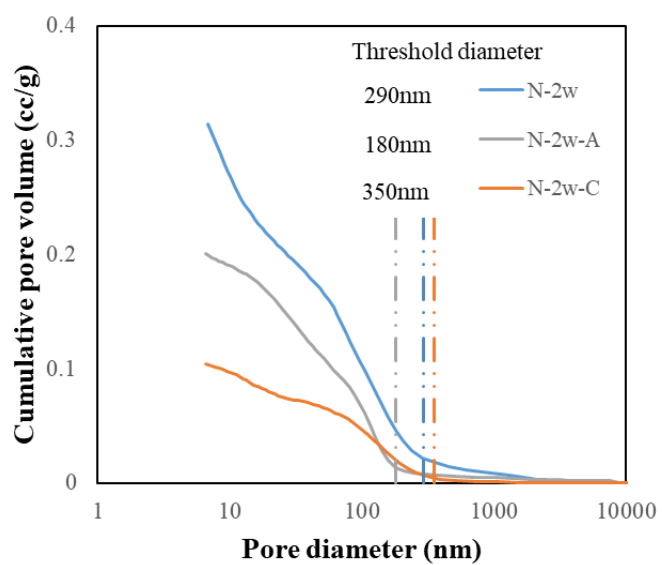

(b)

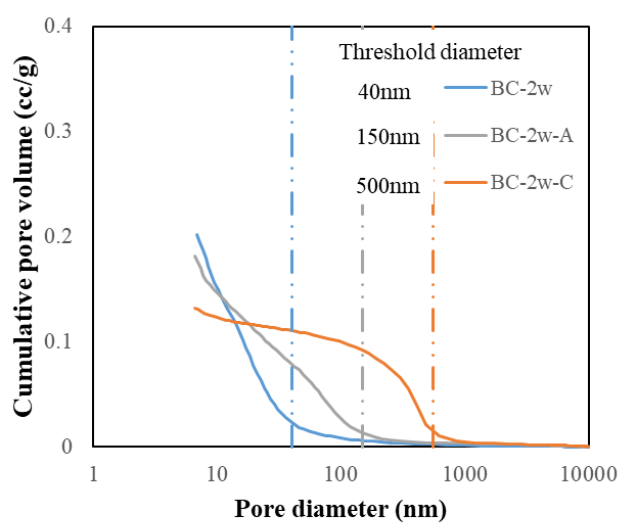

(d)

Figure 8. Cumulative pore volume and threshold diameter of carbonated cement paste. (a) N; (b) BA; (c) BB and (d) BC.

In comparing the air-cured specimen and the carbonated specimen, it was observed that as the replacement rate of BFS increases, the number of pores with a size of $100 \mathrm{~nm}$ or larger tends to increase. The letter $X$ is a carbonated specimen that overlaps with the air-cured specimen. The position of the letter $X$ moves to a smaller pore size as the replacement rate of BFS increases; as a result, the number of pores with a size of $100 \mathrm{~nm}$ or more tends to increase. Such a trend was also found in previous studies, but in the previous studies, the experiment was not based on the replacement ratio of the binder, as the experiment was performed using fly ash. Hence, there was no consideration of this tendency [20]. In this study, the effect of the replacement ratio of the binder was considered, and the effect of the replacement rate of BFS could be confirmed. Furthermore, based on the XRD results, it is determined that the generation of calcium carbonate of different types indicates this tendency. In particular, vaterite is considered to exhibit such a tendency.

\subsubsection{Total Porosity Results}

Figure 9 shows the total porosity of the BFS-blended paste samples at a water curing age of 2 weeks. The specific volume of the paste samples is shown in Table 3. The method of measuring the total porosity of the samples was carried out in the same way as in the previous paper [21]. A vacuum was created to fill the test body full of water. The weight dried at $40{ }^{\circ} \mathrm{C}$ for 2 days were the capillary pores, and the weight dried at $105{ }^{\circ} \mathrm{C}$ for 1 day were the gel pores. In addition, the weight change 
after drying at $105{ }^{\circ} \mathrm{C}$ was measured as the total porosity [21]. Figure 9 is the total porosity for the carbonated (6 weeks), air-cured (6 weeks), and water-cured samples ( 2 weeks). Figure 9 shows the total porosity results with respect to the different BFS replacement ratios after water curing for 2 weeks. It is revealed that the total porosity of paste samples tends to increase as the BFS replacement ratio increases because the proportion of cement content decreases and the reaction rate of BFS is delayed [22-27]. Moreover, in the case of the carbonated paste sample, the total porosity reduced with the level of carbonation, which shows the same tendency as the BFS cement paste, as seen in Figure 9. This is the same result as the cumulative pore volume. Figure 9 shows the total porosity after air curing. The capillary pore volume decreases as the BFS replacement ratio increases. This is due to the same reason as that of the water curing results. The pore structure of each compound and the total porosity results were determined by mercury intrusion porosimetry. It can be concluded that the pore volume could have been shifted towards a large pore volume by carbonation, and the total porosity of the carbonated samples was found to decrease.

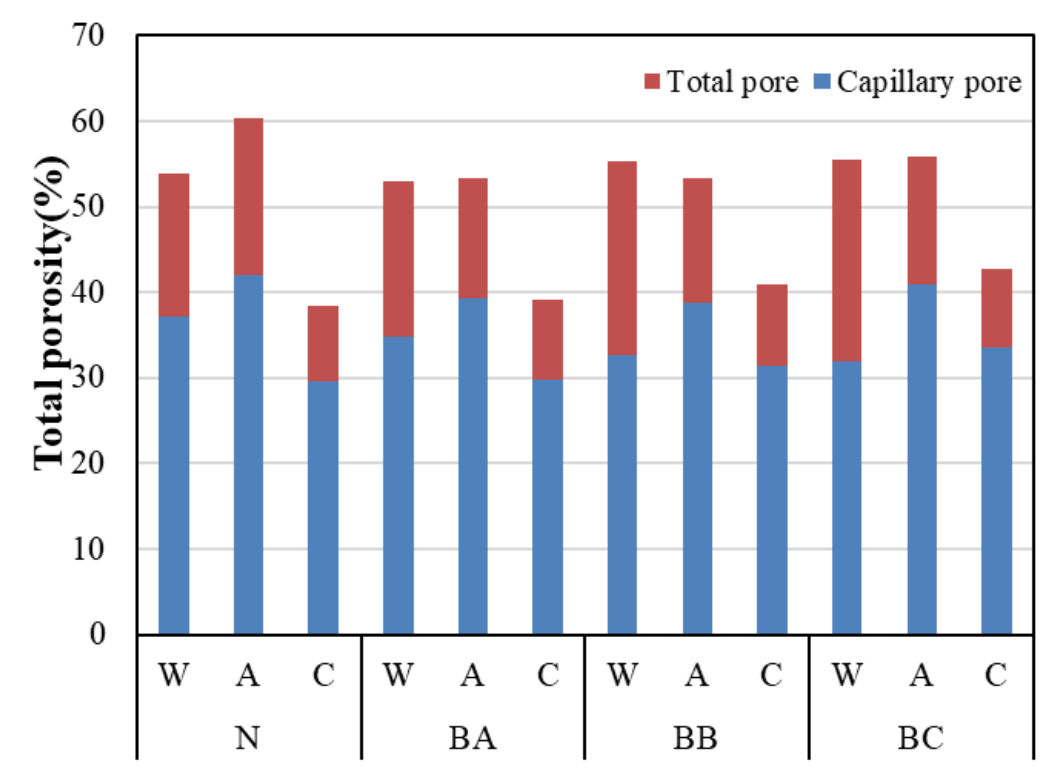

Figure 9. Total pore volume of carbonated cement paste.

Table 3. Specific volume of paste samples.

\begin{tabular}{cccc}
\hline & Water Curing & Air Curing & Carbonation \\
\hline N & 0.37 & 0.29 & 0.37 \\
BA & 0.37 & 0.32 & 0.37 \\
BB & 0.36 & 0.32 & 0.37 \\
BC & 0.36 & 0.32 & 0.37 \\
\hline
\end{tabular}

\section{Discussion of Pores Affecting Durability}

Figure 10 shows the ink-bottle pore volume in BFS-blended paste samples after 2 weeks of water curing. The method of measuring the total pore volume was carried out in the same way as in the previous paper [28,29]. According to the literature, the water in ink-bottle pores acts as a passage for carbon dioxide and influences carbonation. Furthermore, blocking ink-bottle pores lowers the carbonation rate [12]. Therefore, in this study, the higher BFS ratio increased the volume of the ink-bottle pores and tended to decrease the amount of lifting of the ink-bottle pores during the carbonation and air-curing processes. In addition, in the case of the air-cured test specimen, except for the BC specimen, the ink-bottle pore volume was higher than that of the water-cured specimen. In the carbonation test specimen, the volume of ink-bottle pores was significantly lower than that of the water-cured and air-cured specimens. In addition, as the replacement ratio of BFS increased, the volume 
of ink-bottle pores produced during air curing was lower, but there was no significant difference after carbonation. In the literature, the number of ink-bottle pores was determined to influence freezing and thawing resistance. In addition, several studies have shown that ink-bottle pores affect the increase in freeze-thaw resistance $[30,31]$. Therefore, it is determined that the number of ink-bottle pores reduced by carbonation affects the increase in freeze-thaw resistance.

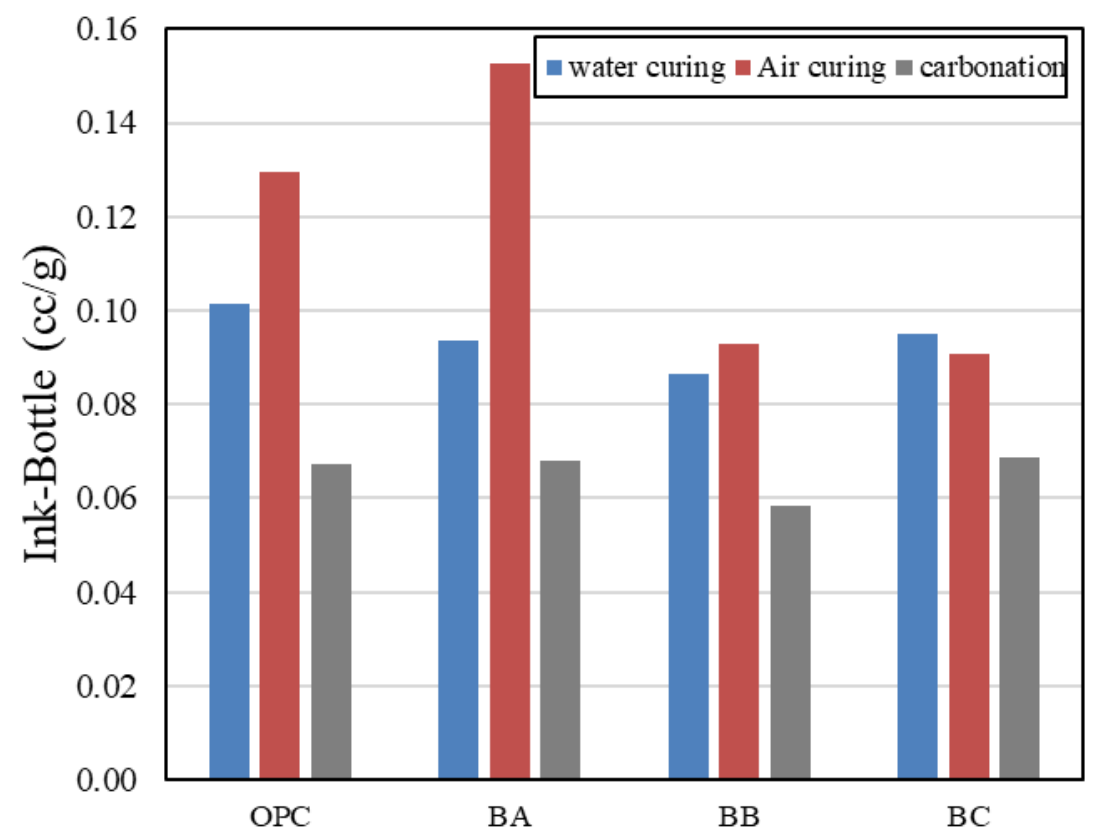

Figure 10. Ink-bottle volume of carbonated cement paste.

Figure 11 shows the pore structure of carbonated cement paste, including the solid volume, in BFS-blended paste samples after 2 weeks of water curing. According to Figure 11, the number of pores with sizes of 40-200 $\mathrm{nm}$ in the air-cured sample increases compared with that of the water-cured sample. In addition, when comparing the air-cured and the carbonation samples, it was confirmed that the number of pores with sizes of $40-2000 \mathrm{~nm}$ is reduced by carbonation, except for the BC specimen. As for the effect of BFS replacement, the higher the BFS replacement ratio, the higher the ratio of pores with sizes of 40-2000 $\mathrm{nm}$ due to carbonation. According to the literature, the number of pores in the size range of $40-2000 \mathrm{~nm}$ influences the freeze-thaw resistance. The freeze-thaw resistance increased as the number of pores in the size range of $40-2000 \mathrm{~nm}$ decreased $[32,33]$. The BC samples were an exception; as the amount of blast-furnace slag increased, the carbonated samples tended to show a lower number of pores with a diameter of $40-2000 \mathrm{~nm}$ than the air-cured samples. However, in this study, it was determined that there is little difference in the number of pores in the size range of 40-2000 $\mathrm{nm}$ in the mortar versus the concrete.

Figure 12 shows the relationship between the $40-2000 \mathrm{~nm}$ pore volume and the ink-bottle pore volume in BFS-blended paste samples after 2 weeks of water curing. There is a significant disparity between the carbonated and air-cured samples. For the air-cured samples, as the total volume of the pores with diameters of 40-2000 nm increased, the total ink-bottle pore volume also tended to increase. However, the carbonated samples, except for the BC-2w sample, showed a lower ink-bottle pore volume and a lower volume of pores with diameters of 40-2000 $\mathrm{nm}$ than the air-cured samples. The freeze-thaw resistance was dependent on the pore structure, and the carbonated samples had a higher freeze-thaw resistance due to the effect of the low ink-bottle pore volume and the low volume of pores with diameters of $40-2000 \mathrm{~nm}$. 


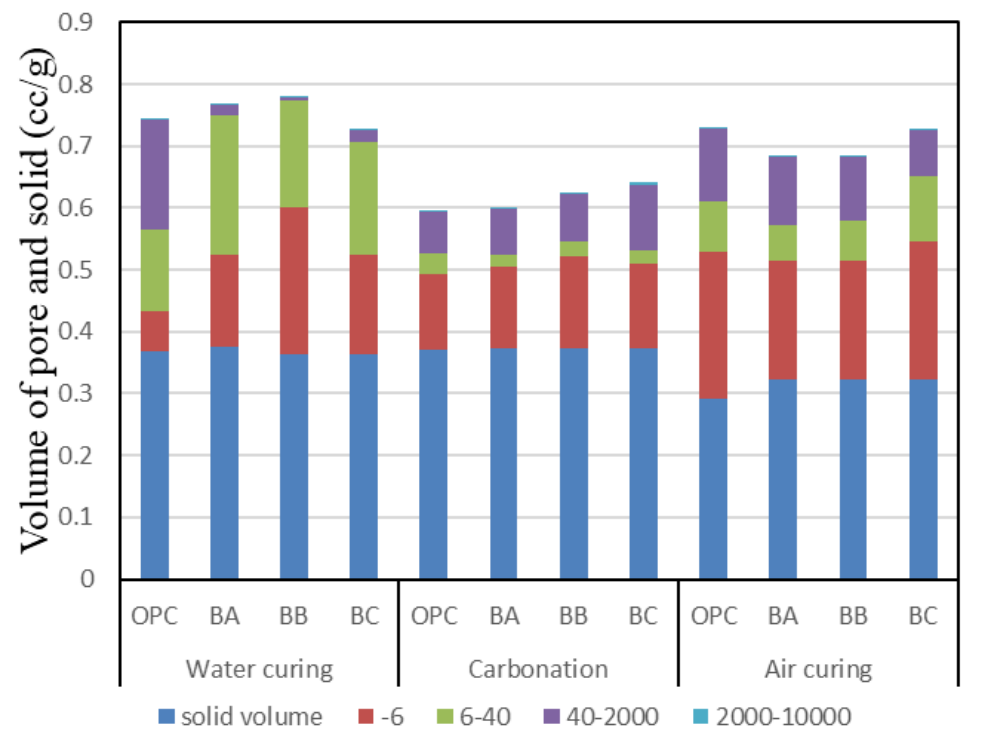

Figure 11. Pore structure of carbonated cement paste.

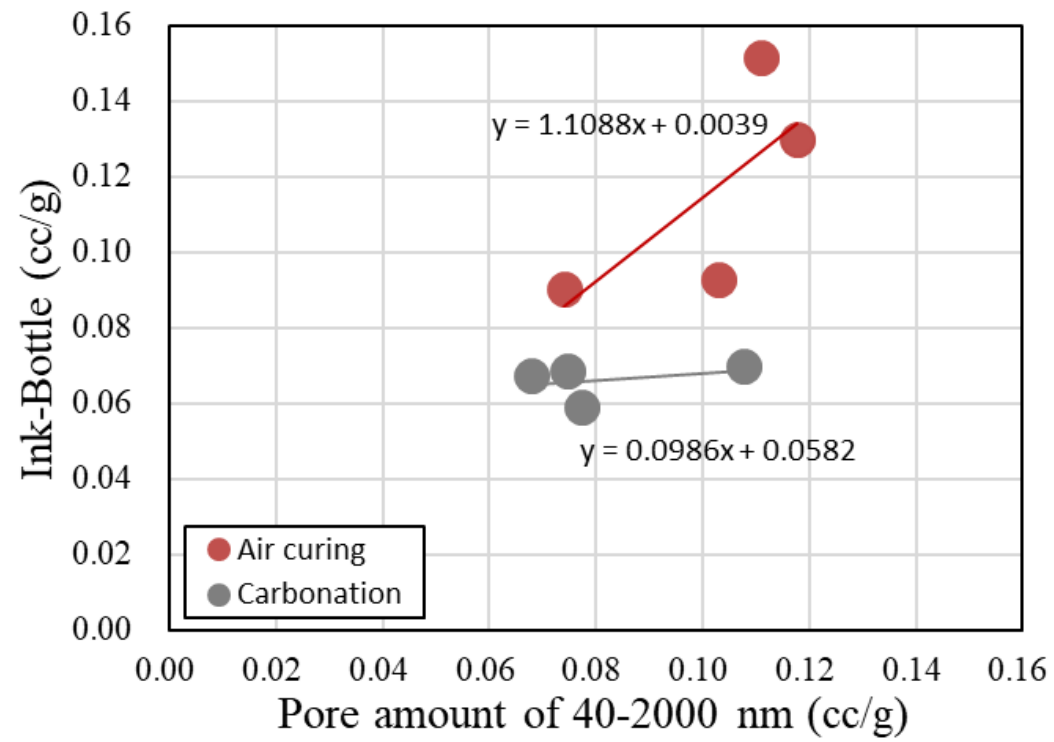

Figure 12. Relationship between $40-2000 \mathrm{~nm}$ pore volume and ink-bottle pore volume in carbonated cement paste.

Figure 13 shows the result for the relationship between the amount of calcium carbonation with capillary pores and the total pore volume in BFS-blended paste samples after 2 weeks of water curing. At the same curing age, the total porosity and capillary porosity of the carbonation test sample decreases compared with that of the air-cured test sample. It can be said that the pore structures in the cement paste were reduced by carbonation.

These results show that the higher the replacement ratio of blast-furnace slag in the cement, the higher the amount of vaterite produced by carbonation. As described above, the lower the $\mathrm{Ca} / \mathrm{Si}$ ratio, the greater the amount of vaterite produced. In this study, as the amount of $\mathrm{Ca} / \mathrm{Si}$ decreased, the amount of vaterite increased as it replaced the blast-furnace slag. In the existing literature, it has been reported that when calcium hydroxide is converted to vaterite, a higher volume expansion ratio is displayed than when calcium hydroxide is converted to calcite. Therefore, it is assumed that the higher the replacement ratio of the blast-furnace slag, the smaller the pore size, which improves freeze-thaw resistance. In addition, when the concentration of hydroxides is high, the precipitation of $\mathrm{Ca}(\mathrm{OH})_{2}$ will 
be promoted and the replacement of Ca-rich sources accelerates both the initial and final setting time of the material $[34,35]$.

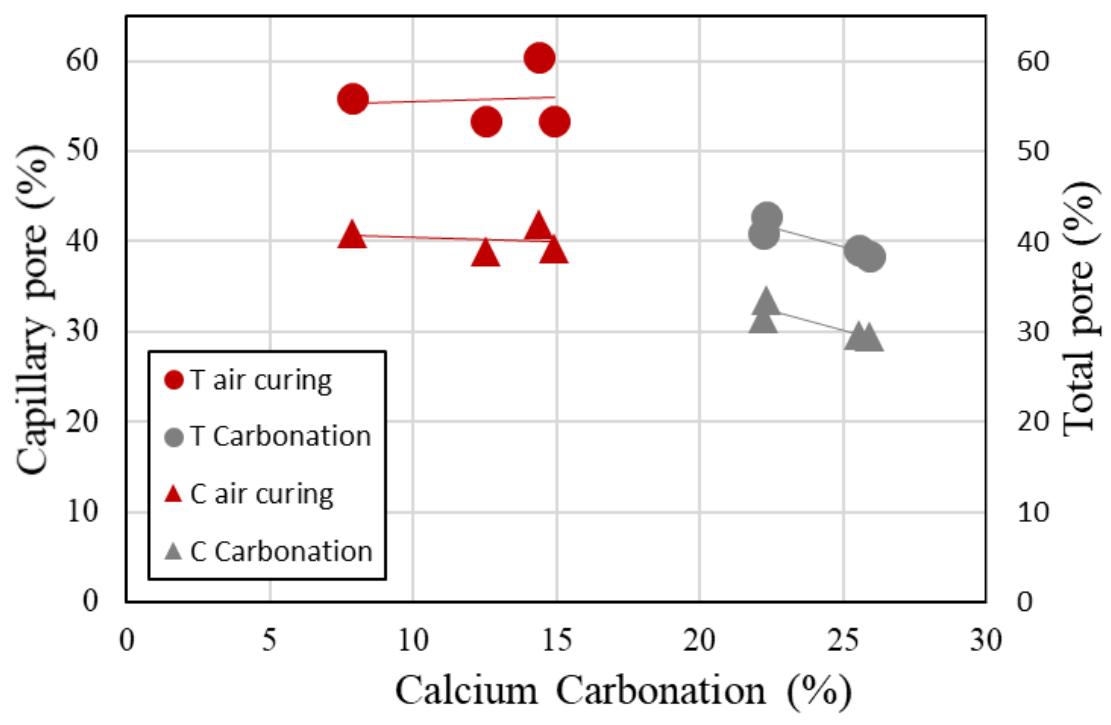

Figure 13. Relationship between the amount of calcium carbonation and the number of capillary pores and total pores in carbonated cement paste.

\section{Conclusions}

In this study, the effect of carbonation on the properties of pore structure change and the chemical properties of BFS cement paste incorporating different BFS replacement ratios were investigated. The carbonation deterioration in cement paste was investigated in this research using mercury intrusion porosimetry, thermal analysis, and X-ray diffraction. However, this study is limited to the chemical composite and pore structure. The influence of carbonation on engineering properties, the dynamics and mechanisms of carbonation, and the differentiation of $\mathrm{CH}$ and $\mathrm{CSH}$ carbonation may be very important, so it is advisable to pursue further research. We will post these results in the future. The primary findings of this study can be summarized as follows:

1. The small pore distribution tends to increase as the BFS replacement ratio increases during water curing. Moreover, it was found that the carbonation of the cementitious composite could enhance the density of the cement paste samples. A shift towards a large pore distribution is caused after carbonation.

2. With respect to the influence of the DTG curve on each curing environment, it is notable that as the BFS replacement rate increased, the peak of the produced CC tended to decrease.

3. With respect to the influence of the amount of $\mathrm{CH}$ and $\mathrm{C}-\mathrm{S}-\mathrm{H}$ on carbonation, the thermal analysis of the carbonation amount from C-S-H increased with the BFS replacement ratios of the BB specimen and the $\mathrm{BC}$ specimen in the carbonation samples.

4. With respect to the influence of the cement mineral composite on the carbonated samples, it is notable that the amount of vaterite in the BFS-blended paste samples is larger than that of the $\mathrm{N}$ samples, and this phenomenon is primarily due to the low $\mathrm{Ca} / \mathrm{Si}$ ratio of the $\mathrm{C}-\mathrm{S}-\mathrm{H}$ phase caused by BFS replacement.

In the future, we aim to clarify the reasons for the rapid pore structure change by incorporating BFS cement paste samples using the XRD/Rietveld quantification method to investigate the degree of mineral change after carbonation.

Author Contributions: Data curation, J.K.; project administration, Y.H.; supervision, Y.H.; writing-original draft, J.K.; writing-review \& editing, S.N. All authors have read and agreed to the published version of the manuscript. 
Funding: This research received no external funding.

Conflicts of Interest: The authors declare no conflict of interest.

\section{References}

1. Tanaka, Y.; Saeki, T.; Sasaki, K.; Suda, Y. Fundamental Study on Density of C-S-H. Cem. Sci. Concr. Technol. 2009, 63, 70-76. [CrossRef]

2. Ishida, T.; Ito, Y.; Kawai, K. Carbonation Characteristics of The C-S-H With Various Ca/Si Ratios. Cem. Sci. Concr. Technol. 2013, 67, 487-494. [CrossRef]

3. Ishida, S.; Igarashi, S.-I.; Koike, Y. Effects of Early-Age Carbonation on Mecanical and Electrical Properties of Cement Pastes and Concretes. Cem. Sci. Concr. Technol. 2011, 65, 282-289. [CrossRef]

4. Saeki, T.; Ohga, H.; Nagataki, S. Change in micro-structure of concrete due to carbonation. Doboku Gakkai Ronbunshu 1990, 420, 33-42. [CrossRef]

5. Li, C.-H.; Nakarai, K.; Ishii, Y.; Yokozuka, K. Experimental Study on Effect of Carbonation of Early Aged Cement Paste on Micro-Pore Structure and Effective Diffusion Coefficient Of Oxygen. Cem. Sci. Concr. Technol. 2009, 63, 99-106. [CrossRef]

6. Phung, Q.T.; Maes, N.; Jacques, D.; Bruneel, E.; Van Driessche, I.; Ye, G.; De Schutter, G. Effect of limestone fillers on microstructure and permeability due to carbonation of cement pastes under controlled $\mathrm{CO}_{2}$ pressure conditions. Constr. Build. Mater. 2015, 82, 376-390. [CrossRef]

7. Borges, P.H.; Costa, J.O.; Milestone, N.B.; Lynsdale, C.J.; Streatfield, R.E. Carbonation of CH and C-S-H in composite cement pastes containing high amounts of BFS. Cem. Concr. Res. 2010, 40, 284-292. [CrossRef]

8. Rostami, V.; Shao, Y.; Boyd, A.J.; He, Z. Microstructure of cement paste subject to early carbonation curing. Cem. Concr. Res. 2012, 42, 186-193. [CrossRef]

9. Zhang, W.Y.; Na, S.H.; Kim, J.H.; Choi, H.G.; Hama, Y. Evaluation of the combined deterioration by freeze-thaw and carbonation of mortar incorporating BFS, limestone powder and calcium sulfate. Mater. Struct. 2017, 50, 171. [CrossRef]

10. Zhang, W.; Zakaria, M.; Hama, Y. Influence of aggregate materials characteristics on the drying shrinkage properties of mortar and concrete. Constr. Build. Mater. 2013, 49, 500-510. [CrossRef]

11. Zhang, W.; Hama, Y.; Na, S.H. Drying shrinkage and microstructure characteristics of mortar incorporating ground granulated blast furnace slag and shrinkage reducing admixture. Constr. Build. Mater. 2015, 93, 267-277. [CrossRef]

12. Kayyali, O.A. Mercury intrusion porosimetry of concrete aggregates. Mater. Struct. 1985, 18, $259-262$. [CrossRef]

13. Karen, S.; Ruben, S.; Barbara, L.I. A Practical Guide to Microstructural Analysis of Cementitious Materials; Taylor and Francis Group: Oxford, UK, 2015.

14. Mo, L.; Hao, Y.; Liu, Y.; Wang, F.; Deng, M. Preparation of calcium carbonate binders via $\mathrm{CO}_{2}$ activation of magnesium slag. Cem. Concr. Res. 2019, 121, 81-90. [CrossRef]

15. Wu, B.; Ye, G. Development of porosity of cement paste blended with supplementary cementitious materials after carbonation. Constr. Build. Mater. 2017, 145, 52-61. [CrossRef]

16. Thiéry, M.; Faure, P.; Morandeau, A.; Platret, G.; Bouteloup, J.-F.; Dangla, P. Effect of carbonation on the microstructure and moisture properties of cement-based materials. In Proceedings of the XII DBMC 12th International Conference on Building Materials and Components, Porto, Portugal, 12-15 April 2011.

17. Jin, S.; Zheng, G.; Yu, J. A micro freeze-thaw damage model of concrete with fractal dimension. Constr. Build. Mater. 2020, 257, 119434. [CrossRef]

18. Li, B.; Mao, J.; Nawa, T.; Han, T. Mesoscopic damage model of concrete subjected to freeze-thaw cycles using mercury intrusion porosimetry and differential scanning calorimetry (MIP-DSC). Constr. Build. Mater. 2017, 147, 79-90. [CrossRef]

19. Vu, T.H.; Gowripalan, N.; De Silva, P.; Paradowska, A.Z.; Garbe, U.; Kidd, P.; Sirivivatnanon, V. Assessing carbonation in one-part fly ash/slag geopolymer mortar: Change in pore characteristics using the state-of-the-art technique neutron tomography. Cem. Concr. Compos. 2020, 114, 103759. [CrossRef]

20. Vineet, S.; Karen, S.; Bishwajit, B.; Shashank, B. Changes in microstructure characteristics of cement paste on carbonation. Cem. Concr. Res. 2018, 109, 184-197. [CrossRef] 
21. Zhang, W.; Zakaria, M.; Kishimoto, Y.; Hama, Y. Drying Shrinkage and Microstructure Characteristics of Ground Granulated Blast Furnace Slag-Cement Mortar; JCI Annual Convention: Hirosima, Japan, July 2012.

22. Çetin, C.; Erdoğan, S.T.; Tokyay, M. Effect of particle size and slag content on the early hydration of interground blended cements. Cem. Concr. Compos. 2016, 67, 39-49. [CrossRef]

23. Barnett, S.; Soutsos, M.; Millard, S.; Bungey, J. Strength development of mortars containing ground granulated blast-furnace slag: Effect of curing temperature and determination of apparent activation energies. Cem. Concr. Res. 2006, 36, 434-440. [CrossRef]

24. Boukendakdji, O.; Kadri, E.-H.; Kenai, S. Effects of granulated blast furnace slag and superplasticizer type on the fresh properties and compressive strength of self-compacting concrete. Cem. Concr. Compos. 2012, 34, 583-590. [CrossRef]

25. Miyazawa, S.; Yokomuro, T.; Sakai, E.; Yatagai, A.; Nito, N.; Koibuchi, K. Properties of concrete using high C3S cement with ground granulated blast-furnace slag. Constr. Build. Mater. 2014, 61, 90-96. [CrossRef]

26. Özbay, E.; Erdemir, M.; Durmuş, H.I. Utilization and efficiency of ground granulated blast furnace slag on concrete properties-A review. Constr. Build. Mater. 2016, 105, 423-434. [CrossRef]

27. Prithika, A.J.; Sekar, S. Mechanical and fracture characteristics of Eco-friendly concrete produced using coconut shell, ground granulated blast furnace slag and manufactured sand. Constr. Build. Mater. 2016, 103, 1-7. [CrossRef]

28. Yoshida, S.; Nawa, T.; Taguchi, F.; Watanabe, H. Influence of Pore Structure on Carbonation of Belite-Based Cement Concrete Using Ground Granulated Blast-Furnace Slag at Low Water/Binder Ratio. Doboku Gakkai Ronbunshuu E 2008, 64, 1-15. [CrossRef]

29. Moro, F.; Böhni, H. Ink-Bottle Effect in Mercury Intrusion Porosimetry of Cement-Based Materials. J. Colloid Interface Sci. 2002, 246, 135-149. [CrossRef]

30. Deprez, M.; De Kock, T.; De Schutter, G.; Cnudde, V. The role of ink-bottle pores in freeze-thaw damage of oolithic limestone. Constr. Build. Mater. 2020, 246, 118515. [CrossRef]

31. Prick, A. Dilatometrical behaviour of porous calcareous rock samples subjected to freeze-thaw cycles. Catena 1995, 25, 7-20. [CrossRef]

32. Shibuya, M.; Atarashi, D.; Hama, Y.; Ueda, N.; Aono, Y. Influence of Curing Condition and Classification of Cement to Change of Pore Structure and Frost Resistance of Mortal. AIJ 2009, 82, 5-10.

33. Aono, Y.; Fumiaki, M.; Sumio, S.; Hama, Y. Influence of Nanostructure Change during Drying on Frost Resistance of HCP. Concr. Res. Technol. 2008, 19, 21-34. [CrossRef]

34. Ghantous, R.M.; Farnam, Y.; Unal, E.; Weiss, J.; Weiss, W.J. The influence of carbonation on the formation of calcium oxychloride. Cem. Concr. Compos. 2016, 73, 185-191. [CrossRef]

35. Ranjbar, N.; Kuenzel, C.; Spangenberg, J.; Mehrali, M. Hardening evolution of geopolymers from setting to equilibrium: A review. Cem. Concr. Compos. 2020, 114, 103729. [CrossRef]

Publisher's Note: MDPI stays neutral with regard to jurisdictional claims in published maps and institutional affiliations.

(C) 2020 by the authors. Licensee MDPI, Basel, Switzerland. This article is an open access article distributed under the terms and conditions of the Creative Commons Attribution (CC BY) license (http://creativecommons.org/licenses/by/4.0/). 